\title{
Mock-up: An Aid in the Different Steps in Aesthetic Dental Treatment
}

\author{
Rozafa Dragusha, PhD Proc. \\ Private Practice, Albania \\ Djemal Ibraimi, CDT \\ Laboratory Owner, Switzerland
}

doi: 10.19044/esj.2016.v12n6p290 URL:http://dx.doi.org/10.19044/esj.2016.v12n6p290

\begin{abstract}
Today, in restorative and prosthodontic dental treatments, the focus is on aesthetics. This involves meeting the needs and expectations of the patient. Failures occur not only as a result of technical problems, but also as a result of poor communication with the patient. To avoid these scenarios that may obligate us to repeat the restoration from the beginning, we can obtain help by using Mock-up. Despite communication with the diagnostic and treatment planning step, Mock-up enables us to control the function of the end result without even beginning the work. It also enables us to do a minimal invasive tooth preparation.

The aim of this study is to use Mock-up to show its effectiveness in communication, planning, and preparation to achieve the demanded aesthetic dental treatment.

Materials and Methods: We prepared mock-up according to wax-up in the second meeting- the treatment planning step. We used a minimal invasive, mock-up guided, preparation technique from the Mock-up accepted by us and the patient.

Results: This easy and practical method enabled us to avoid the intervention in the ultimate restoration. Our result is in accordance with those of other authors: we had minimal preparation, even some unprepared surfaces and satisfied patient.

Conclusions: The use of Mock-up is a simple technique in aesthetic dentistry. Broadly in prosthodontics, it assures us that the work will be functionally and aesthetically successful.
\end{abstract}

Keywords: Aesthetic dentistry, mock-up, minimal invasive preparation, planning 


\section{Introduction}

Dental mock-up is a preparation that shows the end result over the unprepared teeth. It serves as a guide in prosthodontic treatment, and is very important in aesthetic treatment. Depending on the steps, it has taken different names: Mock-up, BFEP (Bonded Functional Esthetic Prototype) (McLaren - 2013), and APT (Aesthetic Pre-evaluative Temporary) (Gurel, 2003).

Therefore, the major reason for aesthetic dental treatment is as a result of the desire of the patient. So when the patient comes to the clinic, the patient already has an idea of what he/she is expecting. Since a patient's satisfaction is a criterion for evaluating a successful treatment, it is important to understand his/her expectations. Therefore, this can be possible only through an easy-to-understand way of communicating with him/her: a threedimensional mock-up over the unprepared teeth. In this step, despite the aesthetic communication, it can also be done the functional control. This control includes the effect of the restoration on the upper lip posture, and the relationship of the smile line with the lower lip, occlusion, and the phonetic.According to authors (e.g. G. Gurel (2003) and P. Magne (2004)), another interesting aid of mock-up is inthe control minimal invasive preparation.There are many ways of preparing it. These ways include: a) free hand direct mock-up in composite; b) mock-up according to the wax-up, with self curing resine; and c) the modern digital designed mockup.Therefore, the aim of this study is to illustrate practically, step by step, three functions of mock-up in Aesthetic Dentistry. They are:

- $\quad$ Trilateral communication of patient-dentist-dental technician

- $\quad$ Preliminary control of the function of the end result

- $\quad$ The guided minimal invasive preparation

I.

\section{Materials and Methods}

First meeting in the clinic involves:

$>$ Collecting data (facial and smile photography sequences, psychological questionnaire, impressions of the situation)

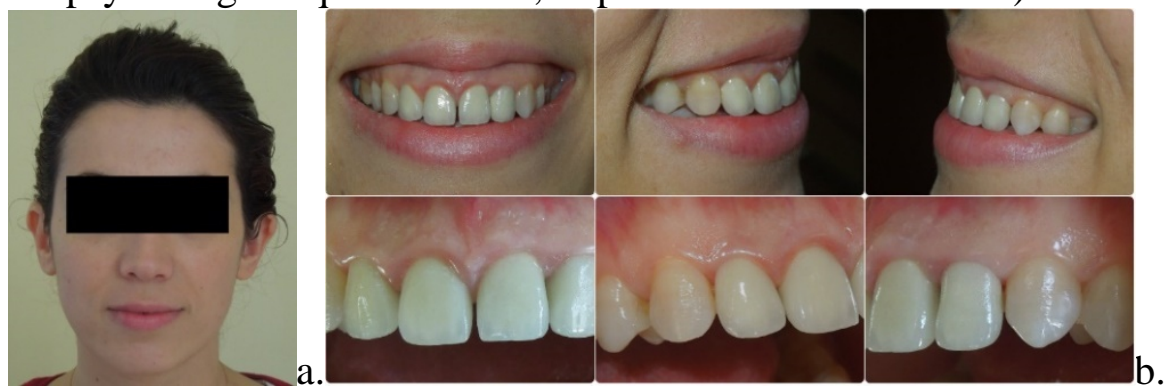

Fig.1. photographic data: a. Facial view; b. Smile photography set 
Psychological questionnaire (Hallawell, 2009) contains many characteristics of the four different types of personality (melancholic, phlegmatic, sanguine, and choleric). The patient, chooses blindly (without knowing which characteristic that belongs to which type of personality) which characteristic she posses. In this way, we were able to understand how she sees herself.

After the meeting with the patient, we:

Analyzed these data (facial and psychological) from which we obtain our suggestion for the treatment plan and the form of the teeth.

So, from the facial analysis (Paolucci B, 2009), the patient (with an oval face, hexagonal but laterally and not vertical) came out to be a combined type between sanguine and melancholic type. However, sanguine type was dominant.

On the other hand, the psychological analysis shows that the patient sees herself as a type with dominance of the melancholic type over the sanguine type.

Based on the conclusion of these results, we suggested a primary project as treatment planning. This project include:

- to change the four frontal zirconia crowns, and to change the form and the color of the canines with porcelain veneers. Accompanied with these detailed suggestions for a personalized smile, the following was put into consideration:

- $\quad$ Vertical axes should be straight or slightly distally inclined

- $\quad$ The line of the zenits should be an inverted parabole

- $\quad$ The incisal plane is in a parabole form

- $\quad$ The lateral incisors should slight present the incisal margin; hence, the distoincisal angle should be curved

- $\quad$ The vestibular ridge of the canine should be curved and medially inclined

- $\quad$ The dental arc should be oval

Through this way, we are ready to communicate with the dental technician (we have the impressions, photographs, and our suggestions)

Communication with dental lab - Wax-up 


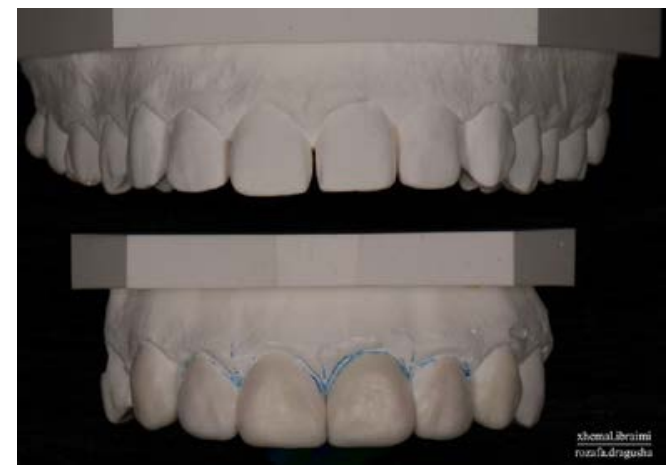

Fig.2. Preparation of Wax-up in dental lab (CDT Djemal Ibraimi)

After getting this information, the dental technician responded to us with a 3D project in wax. Thus, this will aid us in preparing our Mock-Up.

$>\quad$ The silicon key according to wax-up

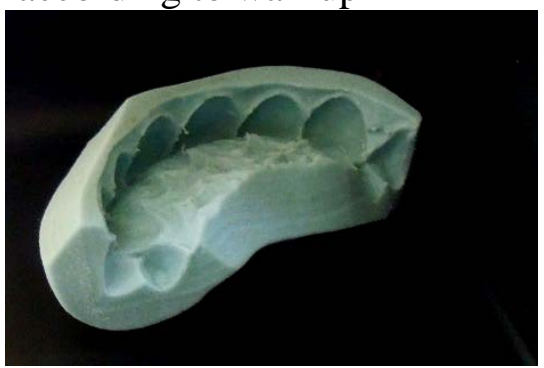

Fig.3. silicon key

Consequently, we made preparation over the model with wax-up, and the negative with silicone: the silicon key

The second meeting in the clinic can be described below:

Mock-Up

We filled the silicone key with the self-curing acrylic to prepare the temporary restorations; inserted it into the mouth; and waited until it cures. Meanwhile, we carefully removed the excess of the material outside the key. After the curing, we removed the silicon key and made any necessary arrangement which could prevent us from having a clear view.

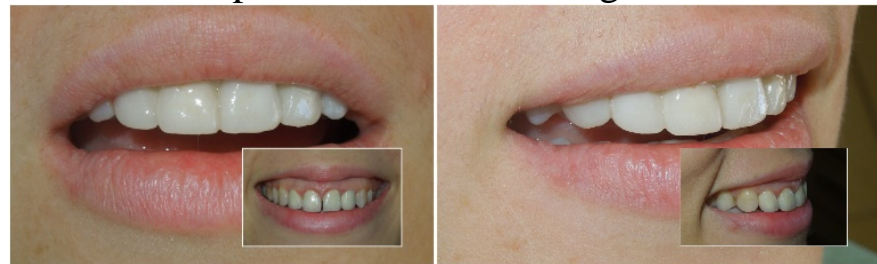

Fig.4. Evaluation of Mock-Up in the mouth (comparing with the actual situation)

$>$ Communication with the patient - taking of the decision for the treatment planning 
The mock-up in the patient's mouth has helped her to understand what was offered to her, and she confronted it with what she was expecting. On the other hand, at the same time, we could control the function, occlusion, the posture of the lip, the smile line, and the phonetics. Surely, we could not only control the aesthetic of the teeth, but especially the harmony with the face in general. We discussed, only for a few changes, the inclination of the long axes of the left lateral incisor.

At the end, we both, with the patient, accepted the treatment plan and the mock-up in total that was suggested.

Preparation over the Mock-Up in the canines for the laminate porcelain veneers.

Since we had nothing to change to the mock-up of the canines, we began the preparation in this step. We did the Galip Gurel method of preparation, over the APT, to achieve a minimal invasion of the teeth (2012).

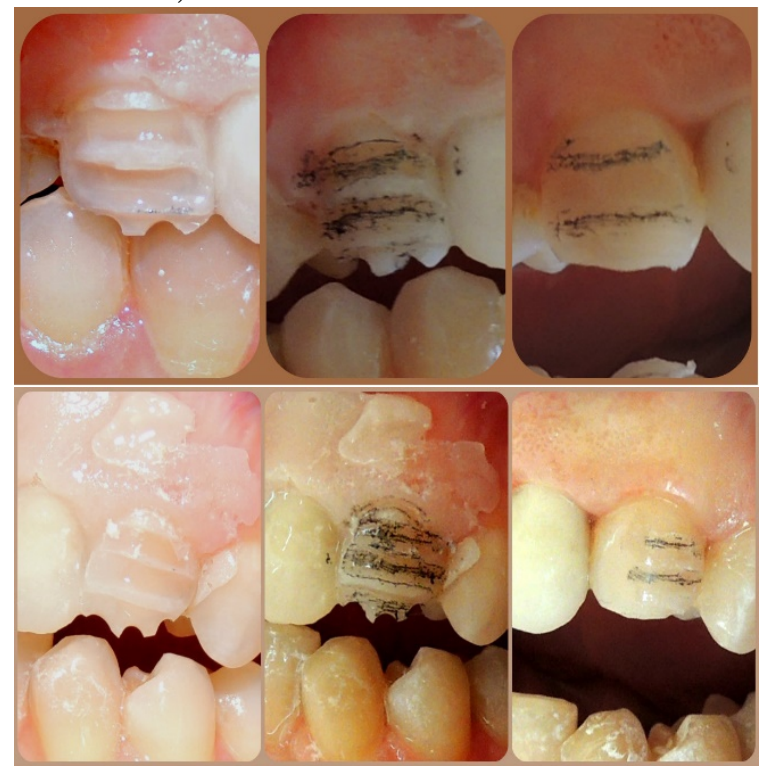

Fig.5. Preparation over mock-up of canines. We noticed that the left canine in the mesial area of the vestibular surface would not need preparation

In addition, we did the guidance grooves over the diagnostic mock-up at a depth of $0.5 \mathrm{~mm}$. Then, we removed the mock-up remnants and continued the preparation which was oriented by the deepness of the grooves. Also, we noticed that in the mesial part of the left canine, we did not need to prepare the tooth. 


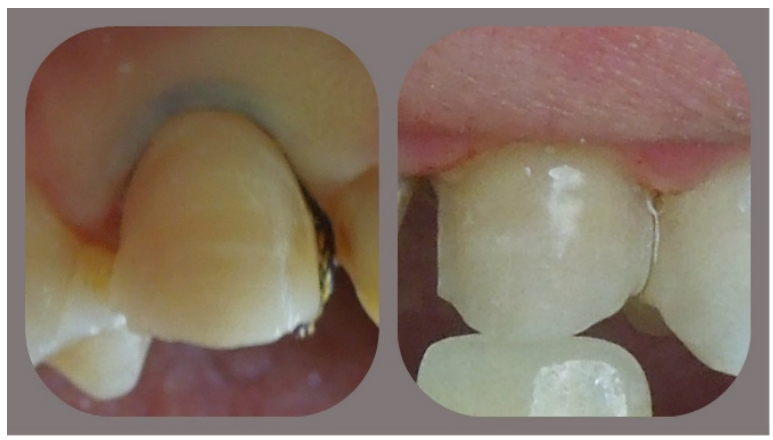

Fig. 6. Preparimi i perfunduar

$>\quad$ Preparation of the temporary restoration

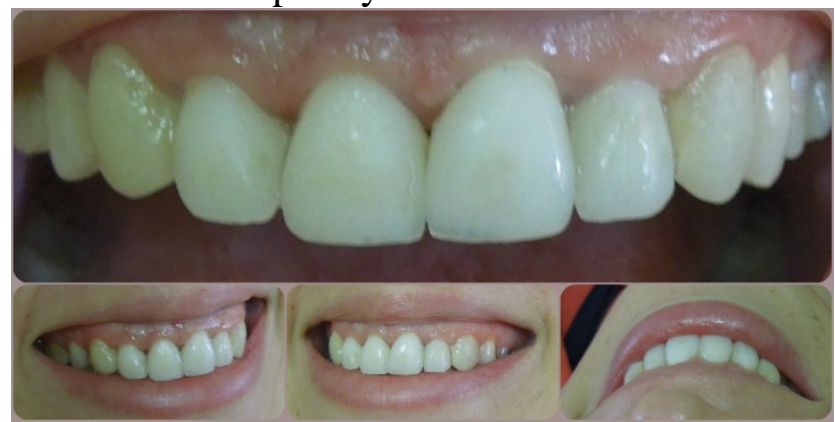

Fig.7. Temporary restoration

After finishing with the preparation and taking impressions, we needed to prepare the temporary restorations. Here, we used the same way of preparing the mock-up. So, we can say that the mock-up can also be used as a temporary restoration. Meanwhile, this helps the patient to get used to the new restoration.

Then, the impressions of the preparations together with the minimal change needed to be done, found in the mock-up (communicated with photography), were sent to the dental laboratory.

The third clinical meeting can be described below:

The final restoration 


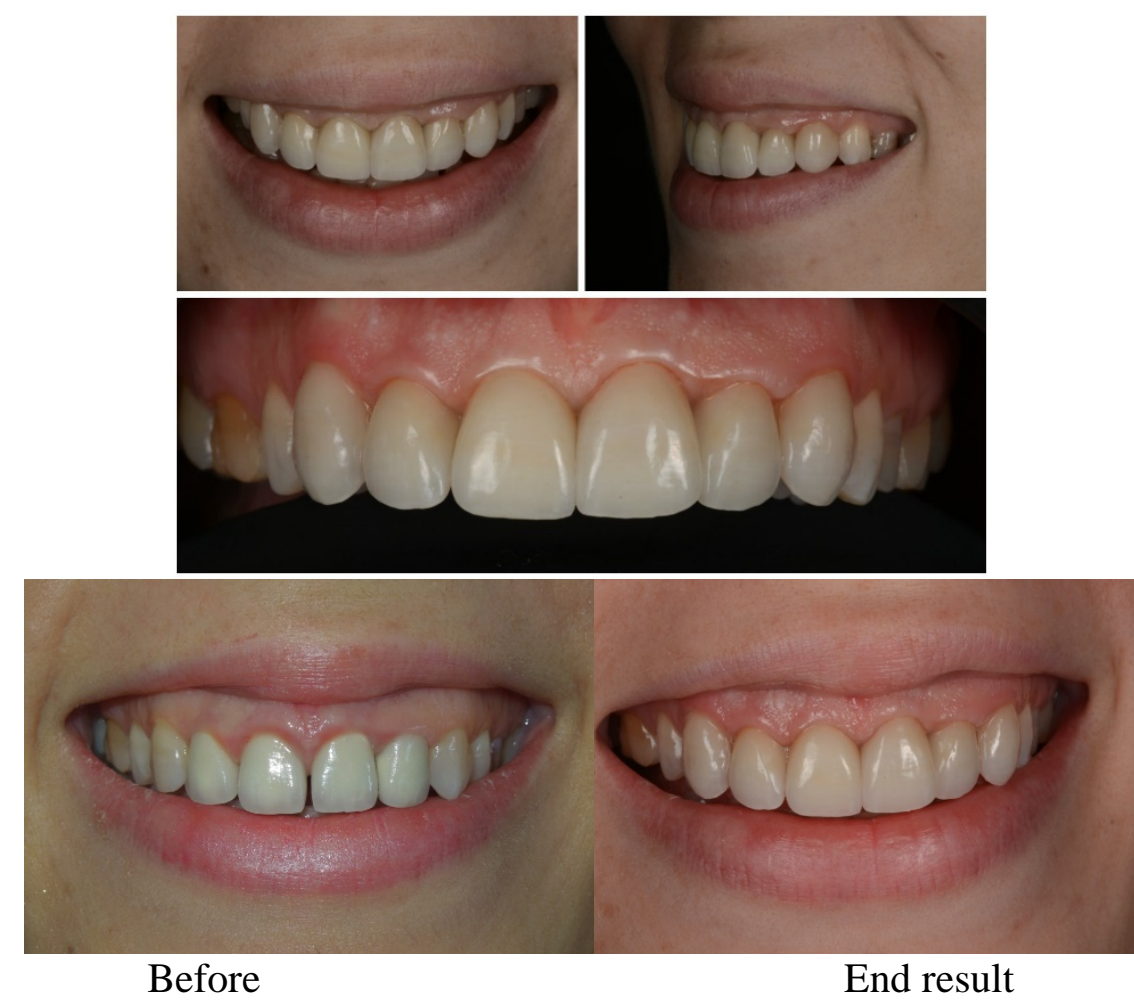

In this step, we had the final result. In addition, we had what we expected and the patient was satisfied.

\section{Results}

The use of Mock-up, without beginning the preparation yet, enabled us to communicate easily with the patient to take the decision for a treatment plan, which gave us the chance to have a satisfied patient with the end result. As a result, we were able to achieve the first and second aim of our study. We also, using the "guided by mock-up" - way of preparation, had the possibility to minimally prepare the teeth, and in some parts not preparing at all, so being maximally conservative, an important fact in conservative dentistry and adhesive dentistry. Through this way, we were able to achieve the third objective of our study.

\section{Discusions}

With the technique of Mock-Up, we are sure of the steps we take during the aesthetic treatment. This is different from the techniques that does not use mock-up.

Furthermore, this discussion might be about the cost of this way. We may say that by avoiding the repeat of each step, especially the repeat of the 
final result (if it could happen in the conventional way), we can say that we can have a controlled cost in terms of time and money

It is very important that through this way, we gain the trust of the patient. This is because since at the first steps of the work, he feels being involved like a collaborator and knows that he would not have bad surprises at the end.

\section{Conclusion}

In conclusion, we can say that mock-up plays an important role in different steps of the aesthetic treatment. These roles include:

- In treatment planning - control of the function (occlusion and phonetics) and aesthetics of the end result, yet without beginning the preparation of the teeth

- $\quad$ In the communication of dentist-patient-dental technician

- $\quad$ In a minimal invasive preparation

- $\quad$ In preparing the temporary restoration

All these aids, has an essential importance to take off every step in a secure way. This is accomplished by having the end result always in mind, giving a major assurance that it will have longevity (minimal invasive preparation) functional and aesthetic (a harmonized agreement about the aesthetic - between the patient and the team) preparation, without even beginning the preparation.

At the end, we will have a happy team - dentist-patient-technician which is the real success of the aesthetic treatment.

\section{References:}

Gurel G (2003). The science and Art of Porcelain Laminate Veneers Chicago: Quintessence.

Gurel et al. (2012). Clinical performance of porcelain laminate veneers: Outcomes of the aesthetic pre-evaluative temporary (APT) technique. Int J Periodontics Restorative Dent; 32:625-635.

Magne P \&Belser UC (2004). Novel porcelain laminate preparation approach driven by diagnostic mock-up. J Esthet Restor Dent; 16:7-18.

Gurel G (2003). Predictable precise and repeatable tooth preparation for porcelain laminate veneers. Pract proceed Aesthetic Dent; 15:17-24.

Gurel G (2007). Porcelain laminate veneers: Minimal tooth prepration by design. Dent clin North Am; 51:419-43.

Reshad M. Cascione D. Magne P. Diagnostic mock-ups as an objective tool for predictable outcomes.

Edelhoff \& Sorensen (2002). Tooth structure removal associated with various preparations designs for anterior teeth. J>Prosthet Dent; 87: 503-509. 
Çotart, Dundar \& Ozturk (2009). The effects of various preparations designs on the survival of porcelain laminate veneers. J Adhes Dent; 11:405-411. Rifkin (2000). Facial analysis: a comprihesive approach of treatment planning in aesthetic dentistry. Pract Periodont Dent; 12(9) 865-87.

Paolucci (2009). Visagismo e Odontologia. In:Hallawell P. Visagismo Integrado: Identidade estilo, beleza. Sao Paulo: Senac; 7:410-7.

Starret et al. (1999). Width/ Length ratio of normal clinical crowns of the maxillary anterior dentition. Man J Clin Periodontal; 26(3): 153-7.

Paolucci B. E colaboradores. Visagismo - A arte de personalizar o desenho do sorriso. Ia Ediçao- Volume1-Sao Paulo 140-4.

Ferrari, Patroni \& Balleri (1992). Measurement of enamel thickness in relation to reduction for etched laminate veneers. Int J Periodontics Restorative Dent; 2(5): 407-413.

Morley (1999). The role of cosmetic dentistry in restoring a youthful appearance J Am Dent Assoc. Aug;130(8):1166-72.

Magne P \& Magne M (2006). Use of additive wax-up and direct intraoral mock-up for enamel preservation with porcelain laminate veneers..Eur J Esthet Dent. Apri1(1):10-9.

Simon \& Magne (2008). Clinically based diagnostic wax-up for optimal esthetics: the diagnostic mock-up. J Calif Dent Assoc. May;36(5):355-62.

Gresnigt, Ozcan \& Kalk (2011). Esthetic rehabilitation of worn anterior teeth with thin porcelain laminate veneers. Eur J Esthet Dent. 2011 Autumn; 6(3):298-313.

Kovacs et al. (2011).Aesthetic smile evaluation--a non-invasive solution. Dent Update. Sep;38(7):452-4, 456-8.

Ercus, Chung \& McLaren (2013). Esthetics with minimal tooth preparation achieved through a digital approach. Compend Contin Educ Dent. Jun; 34(6):428-31.

Furuse et al. (2016). Planning extensive esthetic restorations for anterior teeth: use of waxed-up study casts and composite resin mock-ups. Gen Dent. Jan-Feb; 64(1):e6-9. 